\title{
HISTÓRIA DA EDUCAÇÃO NA AMAZÔNIA. Questões de Natureza Teórico-metodológicas: Críticas e Proposições
}

\author{
Anselmo Alencar Colares \\ Universidade Federal do Oeste do Pará (UFOPA) \\ anselmo.colares@hotmail.com
}

\section{RESUMO}

O texto expressa a posição assumida pelo autor ao compor a mesa redonda que teve como tema: "Local e nacional: questões teórico-metodológicas", durante a IX Jornada do Grupo Nacional de Estudos e Pesquisas História, Sociedade e Educação no Brasil, ocorrida em Belém do Pará, junho de 2010. Questiona a denominação História da Educação na Amazônia, apontando elementos essenciais para que ela possa ser coerentemente efetivada. Sugere uma possibilidade teórico-metodológica para a pesquisa nesta área e aponta os limites presentes em concepções que não admitem que a história possa ser compreendida objetivamente, restando-nos a aceitação das diversas versões apresentadas, independente das fontes, e das análises nas quais se sustentaram. Por fim, apresenta uma contribuição para a escrita da história educacional da Amazônia, tendo como recorte o Grão-Pará na época colonial.

Palavras-Chave: Educação; Amazônia; Concepções teórico-metodológicas.

\section{HISTORY OF EDUCATION IN THE AMAZON. Theoretical and Methodological Issues: Criticism and Proposal}

\begin{abstract}
This text is the result of "round table" organized to discuss the "Local and national: theoretical and methodological issues" during the Ninth Congress of the "Grupo Nacional de Estudos e Pesquisas História, Sociedade e Educação no Brasil," (National Group for Research and Studies in History, Society and Education in Brazil), held in Belem do Para, in June 2010. We question the name "History of Education in the Amazon", pointing essential elements so that it can be consistently effective. We suggest a possible theoretical and methodological research in this area and indicate the present limits on ideas that do not admit that history can be understood objectively, leaving us to accept the different versions presented, regardless of funding, and analysis on which it is claimed. Finally, we propose to offer a contribution to the writing of educational history of the Amazon, focusing on the Grao Para in colonial times.

Keywords: Education; Amazon; theoretical and methodological concepts.
\end{abstract}

\section{Introdução}

As reflexões e proposições a seguir apresentadas decorrem da minha vivência enquanto professor da disciplina História da Educação, desde 1996, na Universidade Federal do Pará - UFPA, da trajetória posterior incluindo os estudos de mestrado e doutorado na Universidade Estadual de Campinas - UNICAMP (área de história da educação) e um período de quatro anos em que exerci a docência na Universidade Federal de Rondônia - UNIR. Ressalte-se que neste percurso sempre houve uma incessante busca pela compreensão do fenômeno educacional na região em que exerço minhas atividades: a 
Amazônia. Portanto, busco respostas para questões que emergiram da própria atividade docente.

No mestrado, desenvolvi a dissertação intitulada "Sociedade e educação em Santarém-Pa: estudo do período em que o município foi área de segurança nacional (19691984)". Após a defesa, que aconteceu em agosto de 1998, regressei a Santarém e reassumi as turmas do curso de Pedagogia, o qual estava em processo de intensas mudanças curriculares. Entre outras novidades, a matéria história da educação deixou de ser subdividida em três disciplinas (História I, desde a educação nas comunidades primitivas, passando pelas civilizações clássicas, até o Renascimento; História II, da Época Moderna até a atualidade, destacando as idéias e práticas pedagógicas; História III, a educação no Brasil, dos jesuítas até os dias atuais) e passou a ser desenvolvida em apenas duas disciplinas, História Geral da Educação e História da Educação Brasileira e da Amazônia ${ }^{l}$. Com esta modificação ficou mais claro e enfático o propósito da presença da temática regional nos estudos histórico-educacionais, assim como aumentou a responsabilidade dos docentes/pesquisadores em buscar subsídios para o desenvolvimento das aulas, através da realização de pesquisas destinadas à construção da história da educação em âmbito regional, dada a bibliografia existente ser incapaz de dar conta, com propriedade, do objeto de estudo proposto na referida disciplina. Os docentes da disciplina viram-se diante do seguinte impasse: simplesmente inferir que as análises já realizadas por pesquisadores da história da educação brasileira com relação a outras regiões também se aplicam à Amazônia, ou buscar produzir conhecimentos considerando as singularidades desta região.

A tese de doutorado, em grande medida, voltou-se para a produção de um texto que pudesse subsidiar estudantes e pesquisadores no desenvolvimento da disciplina História da Educação no Brasil e na Amazônia. Por conseguinte, busquei reunir e analisar as fontes disponíveis à luz de um referencial teórico que auxiliasse no desvelamento do que se encontra por trás das simples aparências ou mesmo que pudesse elevar a compreensão para além das analogias com o já apreendido sobre outras regiões. Tarefa inconclusa, todavia não abandonada. Continuo empreendendo esforços no sentido de contribuir para com a escrita da história da educação dos espaços nos quais tenho exercido minha atividade profissional. Mas desde já cabe fazer uma ressalva: Não se trata de produzir ou incentivar a produção de uma história em que os acontecimentos locais sejam considerados autônomos e desvinculados dos grandes projetos que movem os interesses mais amplos e que ultrapassam o ambiente e as relações sociais da localidade específica que esteja sendo objeto de estudo. Ao contrário, a busca permanente é movida pela compreensão de que há uma profunda interrelação entre o particular e o geral.

Ao aceitar o convite para compor esta mesa-redonda voltada para o tema LOCAL E NACIONAL: questões teórico-metodológicas ${ }^{2}$, desde o primeiro momento fiquei entusiasmado com a idéia de poder compartilhar com outras pessoas igualmente interessadas em compreender a sua "aldeia", todavia, reconhecendo que ela é, desde muito, global, no sentido de ser parte de um todo. Esta condição inicial traz uma série de implicações de ordem teórica e metodológica, que vou procurar apontar e analisar a seguir, onde dou ênfase para três aspectos que considero fundamentais e nos quais vou buscar legitimar a minha argumentação.

Primeiro: Falar de local e nacional em nossa área de conhecimento implica na busca pela compreensão de um objeto, que é o fenômeno educacional, manifestado historicamente, em uma dada realidade de tempo e um determinado espaço. No nosso caso específico, a Amazônia. Disto tem resultado a utilização cada vez mais acentuada e irrefletida da expressão "História da Educação na Amazônia", ou simplesmente "Educação na Amazônia" nos textos que se reportam a estudos e pesquisas de âmbito local, como se o 
simples fato do objeto estudado estar situado geograficamente nesta Região seja suficiente para garantir-lhe tal particularização. Ora, isto poderia nos levar a admitir que, analogicamente, estudos centrados em outras regiões, resultariam em uma História da Educação do Nordeste, do Sul, do Centro-Oeste, do Sudeste, e tantas outras quantas sejam as expressões utilizadas para caracterizar uma determinada área geográfica.

Portanto, a questão inicial que aponto é a seguinte: Temos elementos justificadores convincentes no campo acadêmico científico para o uso desta expressão designativa "da Amazônia" em nossas produções? Ou esta expressão tem sido utilizada apenas para legitimar o olhar fragmentado e parcial do objeto (educação), desconsiderando-o como produto de múltiplas determinações no tempo e no espaço?

Reputo da maior importância os estudos e as pesquisas centrados em objetos que estão mais próximos da nossa realidade, até para que possamos com maior precisão entender e agir sobre ela. Todavia, não vejo como a educação (notadamente a educação escolar) possa ser compreendida isolada dos fins e objetivos a que se destina. Ambos são aspectos que extrapolam a localidade geográfica em que ela é realizada. Portanto, o local não pode prescindir do regional, do nacional, e até mesmo do internacional. Em outros termos, penso que há necessidade permanente de articular o singular e o universal para o melhor entendimento de nosso objeto de estudo. Não basta a presença do termo Amazônia para que em um texto sobre a educação, o referido fenômeno se apresente diferenciado do que ocorreu e vem ocorrendo em outras regiões do Brasil e do mundo. Mas, em utilizandoo, temos o dever de explicitar as singularidades, as questões específicas, sem reduzi-las a um rol descritivo de situações pitorescas, algo similar ao que Dosse (1992) critica como sendo uma história em migalhas.

Segundo: Refletir sobre a Amazônia implica reconhecer a complexidade que se expressa na sua vasta territorialidade. Trata-se de um conceito construído, arbitrário, carregado de intencionalidades e de historicidade. O espaço geográfico amazônico passou e continua passando por diversas alterações, sendo que as mais significativas correspondem aos contextos de investida na busca de riquezas. A fauna e a flora, assim como a composição química do solo, do sub-solo, das águas e do ar, também se alterou e continua sendo alterada, e os estudos nestes campos mostram-nos que não há uma Amazônia "cristalizada". O espaço amazônico está em construção.

Da mesma forma, a composição humana amazônica é dinâmica, múltipla, e em vários aspectos, singular, e ainda pouco conhecida, especialmente se considerarmos a amplitude do território e as grandes irregularidades na presença humana. Há estudos significativos neste particular, em diversas áreas do conhecimento, mas não raro nos deparamos com análises nas quais a parte é tomada pelo todo, e a caracterização populacional de um "pedaço" da Amazônia é utilizada como expressão representativa da região como um todo. Nesse sentido, apontamos a necessidade de incluirmos a pluralidade humana amazônica e sua distribuição pelo vasto e diferenciado território da Região, para que possamos aplicar a expressão Amazônia. Do contrário, teremos que especificar a qual "das amazônias" estamos nos referindo.

Melhor explicitando: Entendo que não é coerente falar de educação da Amazônia (em sentido amplo) em um estudo que ficou circunscrito, por exemplo, a Belém do Pará. Por mais que esta localidade seja um marco na história da Amazônia, e que nela se encontre pessoas e situações cotidianas ilustrativas da diversidade regional, não é suficiente para permitir uma tamanha generalização. O mesmo se aplica para qualquer outro fragmento territorial, mesmo que de maior extensão, como por exemplo um dos estados que compõem a Região. 
Considerando as duas questões até agora apontadas vou partir para o próximo aspecto que, além de analítico das questões teórico metodológicas, carrega um tom propositivo.

Terceiro: Produzir História da Educação da Amazônia exige uma atitude de diálogo com o já existente e de articulação com os que se dispõem a compreender a região, em seus múltiplos aspectos. Isto implica dizer também que se trata de um empreendimento coletivo. Lançar mão de resultados de outros estudos nos mais diversos campos do conhecimento, e que lançam luzes para a compreensão do fenômeno educacional. Tarefa impossível para um pesquisador isolado, por mais estudioso, organizado, dedicado e competente que seja. Daí a importância e a relevância da formação de grupos de estudos e pesquisas de âmbito local, com objetos específicos. Ao mesmo tempo, tomando-se cautela para que não percamos de vista as relações do singular com o universal, uma vez que o estudo do cotidiano desvinculado da história é uma mistificação.

Feitas estas incursões gerais e introdutórias, vou adentrar-me mais especificamente nas questões de natureza teórico-metodológicas, já assumindo que não se trata de uma descrição e análise de teorias e métodos, e sim da explicitação de uma concepção que entendo ser coerente com os pontos que acima elenquei como importantes e indispensáveis para a compreensão do singular sem perder de vista o universal (ou as relações entre o local e o nacional, conforme consta na programação do evento). E vou encerrar minha exposição utilizando-me de passagens do texto que elaborei objetivando obter minha titulação de doutor de educação, e que intitulei "Colonização, catequese e educação no Grão-Pará" (Tese disponível na página eletrônica da Unicamp, no seguinte endereço: http://www.unicamp/br/bc (biblioteca digital: http://cutter.unicamp.br/).

\section{O materialismo histórico dialético aplicado na compreensão do fenômeno educacional}

Entendemos que para que possamos compreender a educação, faz-se necessário situá-la no interior do movimento histórico da sociedade. Desta forma, ao buscar as raízes do nosso processo de desenvolvimento, podemos identificar melhor determinadas particularidades que adquirimos, assim como, perceber os momentos de ascensão e declínio nesse processo, com seus respectivos componentes e implicações para a educação.

O materialismo histórico, desenvolvido por Marx e Engels, funda-se no imperativo do modo humano de produção social da existência. Com base na exposição apresentada na obra A ideologia alemã, podemos assim resumir esta assertiva: 1) A produção dos meios que permitam satisfazer as necessidades humanas é condição básica e indispensável para a existência do homem e de tudo o que ele possa criar; 2) A ação de satisfazer a necessidade inicial e o instrumento utilizado para tal conduzem a novas necessidades; 3) Os homens se reproduzem, o que também dá origem a novas necessidades, dentro de um quadro social; 4) Consequentemente, deve-se estudar e elaborar a história dos homens em estrita correlação com a história da indústria e das trocas (MARX e ENGELS, 1986, p. 33-35). Assim, o método está vinculado a uma concepção de realidade, de mundo e de vida. Funciona como mediador no processo de entender a estruturação, o desenvolvimento e a transformação dos fenômenos sociais, dos objetos que investigamos.

A dialética, enquanto elemento da natureza, não foi criada ou inventada pelo marxismo, é algo que existe de forma objetiva, independentemente do sujeito. Embora seja possível falar de uma dialética da natureza, não faz sentido falar em dialética sem o homem, uma vez que é na interação homem-natureza que se constrói o conhecimento. Como observa Lefebvre $(1979,21-22)$ " [...] só existe dialética (análise dialética, exposição ou 'síntese') se existir movimento; e [...] só há movimento se existir processo histórico: 
história. Tanto faz ser a história de um ser da natureza, do ser humano (social), do conhecimento!"

Na perspectiva materialista histórica e dialética de Marx e Engels o universo e tudo o que nele há tem existência material, concreta, e pode ser racionalmente conhecido e, por conseguinte, o conhecimento, produzido objetivamente pelo sujeito, deve ter como meta a reprodução do real, em suas múltiplas determinações. Mas para que isto seja alcançado é preciso ultrapassar o nível da aparência, da superfície imediata das coisas e atingir a essência. Esta é uma tarefa complexa, porque a realidade apresenta-se como um todo caótico, sendo que através da abstração é possível analisar as partes, reconstruindo o concreto real que está na base de todo o conhecimento. Faz-se necessário partir do dado empírico, factual, e buscar entender os processos presentes nos fenômenos estudados. Isso significa que inevitavelmente o sujeito está autoimplicado no objeto. Não há uma relação de exterioridade, há uma relação de autoimplicação, que não é uma relação de identidade, mas uma relação de unidade. A realidade social é um complexo constituído de complexos. Isso significa dizer deve haver no pesquisador o permanente cuidado com a especificidade, sem descuidar de suas relações com a totalidade, o que impõe a necessidade da mediação enquanto categoria teórica central na compreensão dos fenômenos sociais. (PAULO NETTO, 1998, p. 58-60).

O que os homens são coincide com a sua produção, tanto com aquilo que produzem como com a forma como produzem. Portanto, a sociedade produz o homem, mas também é produzida por ele. Assim, a consciência é uma abstração da vida real, sendo produto da atividade humana, dai admitir que não é a consciência que cria a vida, mas a vida que, sob condições sociais reais, cria a consciência.

A produção das idéias, de representações e da consciência está em primeiro lugar direta e intimamente ligada à atividade material e ao comércio material dos homens, é a linguagem da vida real. São os homens que produzem as suas representações, as suas idéias, etc., mas os homens reais, atuantes e tais como foram condicionados por um determinado desenvolvimento das suas forças produtivas e do modo de relações que lhe corresponde, incluindo até as formas mais amplas que estas possam tomar. A consciência nunca pode ser mais que o Ser consciente; e o Ser dos homens é o seu processo de vida real. [...]

Contrariamente à filosofia Alemã, que desce do céu para a terra, aqui parte-se da terra para atingir o céu. Isto significa que não se parte daquilo que os homens dizem, imaginam e pensam, nem daquilo que são nas palavras, no pensamento, na imaginação e na representação..., parte-se dos homens, da sua atividade real. É a partir do seu processo de vida real que se representa o desenvolvimento dos reflexos e das representações ideológicas deste processo vital [...] (MARX e ENGELS, 1986, p. 25-26).

Portanto, fica claro que o postulado materialista está presente tanto do ponto de vista ontológico quanto gnosiológico; isto é, a matéria é considerada básica tanto como princípio explicativo do mundo, quanto como ponto de partida para o conhecimento que se constrói sobre ele. Para o materialismo histórico só é possível compreender um determinado fenômeno social em seu processo de transformação. O próprio homem (não isoladamente, mas enquanto humanidade) só pode ser entendido como ser social e histórico que, embora determinado por contextos econômicos, políticos e culturais, é também o criador da realidade social e o transformador desses contextos. A partir deste quadro, esta concepção 
[...] sustenta que o conhecimento efetivamente se dá na e pela práxis. A práxis expressa, justamente, a unidade indissolúvel de duas dimensões distintas, diversas no processo de conhecimento: a teoria e a ação. A reflexão teórica sobre a realidade não é uma reflexão diletante, mas uma reflexão em função da ação para transformar (FRIGOTTO, 1991, p. 81).

O Capital é a principal obra de Marx e também a obra da sua maturidade intelectual. Nela ela faz uma crítica da economia política. Observa que os economistas (especialmente ingleses) tratavam a mercadoria como tendo vida própria, fetichizada (adquirindo propriedades humanas), desconsiderando as relações sociais ai embutidas. Partindo da compreensão de que a sociedade nada mais é do o conjunto de relações sociais, observa que enquanto nas sociedades escravista e feudal havia uma relação absolutamente visível entre as classes, por conta do estatuto da desigualdade, ao passo que na sociedade capitalista as relações entre os homens é velada, transformando-se em relações entre coisas (mercadorias), uma vez que nestas há um estatuto de igualdade (ideário burguês, todos iguais perante a lei, liberdade, fraternidade), ou seja, uma exploração entre iguais. Cabe portanto à ciência, à teoria, desvelar essa realidade. Demonstra que é somente a partir das sociedades mais desenvolvidas que é possível compreender as menos desenvolvidas (a anatomia do homem explica a anatomia do macaco, mas o inverso é impossível). Ao analisar a sociedade capitalista, pretendia possibilitar à humanidade, e ao proletariado em particular, compreender as leis que regem a história para que pudessem lutar e sair da necessidade para a liberdade. Para ele, o confronto entre a burguesia e o proletariado levaria à desagregação do capitalismo. Assim como a burguesia foi a classe revolucionária no interior do feudalismo, o proletariado constitui-se na classe revolucionária no interior do capitalismo, buscando a construção de uma sociedade sem classes. Nos Manuscritos econômicos e filosóficos, afirma que o trabalhador fica mais pobre a medida que produz mais riqueza, e sua produção cresce em força e extensão pois a desvalorização do mundo humano aumenta na razão direta do aumento de valor do mundo das coisas. Eis aí a contradição do capitalismo.

Considerando-se que a sociedade na qual vivemos - quase dois séculos após a formulação do método dialético materialista histórico - permanece estruturada e organizada sob o modo de produção capitalista, podemos daí afirmar que esta concepção continua válida para todos aqueles que buscam conhecer a realidade e, acima de tudo, transformá-la, empenhando-se no projeto coletivo de construção de uma sociedade erigida sob novas bases, na qual sejam superadas todas as formas de exploração humana. Michael Löwy, citando Rosa Luxemburgo, desenvolve com maestria o argumento da atualidade do marxismo:

[...] Os pensadores burgueses, escreve ela com ironia, procurando em vão desde muito tempo um meio de superar o marxismo, não se aperceberam que o único meio verdadeiro se acha no seio da própria doutrina marxista: 'Histórica até o fim, ela não pretende ter senão uma validade limitada no tempo. Dialética até o final, ela carrega em si mesma o germe seguro de seu próprio declínio'. A teoria de Marx corresponde a um período determinado de desenvolvimento econômico e político: 'a passagem da etapa capitalista à etapa socialista da humanidade'. É apenas na medida em que esta etapa for superada, e as classes sociais desaparecerem, que se poderá ir além do horizonte intelectual representado pelo marxismo [...] (LÖWY, 1987, p. 121-122)

Outras concepções históricas muitas vezes se apresentam mais completas e atualizadas por propiciarem o estudo de novos objetos, aceitarem novas abordagens e 
utilizarem-se de novas fontes. Mas não são estes os problemas de fundo. Por exemplo, ganha cada vez mais importância a ampliação das fontes para a compreensão histórica da educação, indo além dos documentos oficiais que por muito tempo foram considerados os únicos confiáveis. Todavia, é necessário que as próprias fontes sejam submetidas a um processo de problematização, no qual se busque compreender o contexto no qual ela foi elaborada, os sujeitos envolvidos no que se refere a autoria e destinatários, quais seus objetivos, seus alcances e seus limites. Vejamos a advertência presente na transcrição a seguir:

As fontes são fundamentais para a sistematização do conhecimento histórico e a análise dos acontecimentos. Identificar, classificar e interpretar as fontes são inerentes a produção histórica e essenciais para a qualidade da pesquisa nesta área do conhecimento. Todavia, as fontes não falam por si, como apregoaram os positivistas. Elas precisam ser "provocadas" pelo pesquisador. A fonte é, desta forma, também uma construção do pesquisador, na medida em que este atribui para ela um determinado sentido. Por outro lado, constitui-se no único elo com o passado, no sentido de verificação, por isso mesmo pode ser entendida como uma ponte, um veículo, uma testemunha, um elemento propiciador de conhecimentos acertados sobre o passado. (RAGAZZINI, 2001, p. $14)$.

Em entrevista concedida a Dalton José Alves e Nailda Costa Bonato, para a revista Acervo, do Arquivo Nacional, o professor emérito da Unicamp, Dermeval Saviani, ao ser interrogado sobre o uso de "novas fontes" teceu as seguintes considerações:

Preliminarmente, cabe considerar que, rigorosamente falando, a multidão de papéis que se acumulam nas bibliotecas e nos arquivos públicos ou privados, as milhares de peças guardadas nos museus e todos os múltiplos objetos categorizados como novas fontes pela corrente da "nova história" não são, em si mesmos, fontes. Com efeito, os mencionados objetos só adquirem o estatuto de fonte diante do historiador que, ao formular o seu problema de pesquisa, delimitará aqueles elementos a partir dos quais serão buscadas as respostas às questões levantadas. Em conseqüência, aqueles objetos em que real ou potencialmente estariam inscritas as respostas buscadas se erigirão em fontes com base nas quais $o$ conhecimento histórico poderá ser produzido. Nesse sentido, já que é sobre as fontes que nos apoiamos para produzir o conhecimento histórico, uma vez formulado o problema a ser investigado, o pesquisador encontrase autorizado a buscar todo tipo de fonte que possa trazer informações de alguma importância para o esclarecimento de seu problema de pesquisa. Portanto, nenhum caminho, nenhuma espécie de fonte lhe pode estar interditada, seja ela nova ou velha, antiga ou moderna [...] (SAVIANI, 2010, p. 255).

Ao conclui suas observações, deixa consolidada sobre posição a respeito do papel das fontes no processo de apreensão do objeto para sua conseqüente compreensão:

[...] O cuidado, pois, que se deve ter é não se deixar inebriar pela suposta novidade das fontes, o que levaria a inverter os termos da questão: em vez de o objeto, isto é, a natureza do problema a ser investigado, determinar a busca das fontes, a própria fonte, em virtude do poder de atração a ela atribuído, é que se converteria em objeto de pesquisa. (idem, p. 255-256). 
No tópico a seguir, discorro sobre o desenvolvimento histórico inicial da educação no Grão-Pará, com a intenção propositiva de contribuir para com a escrita de uma história da educação na Amazônia, lançando mão dos itens que elenquei na introdução. Ressalte-se que no período ao qual me reporto ainda não havia sido consagrada a expressão Amazônia como designativa do território.

Primórdios da educação no Grão-Pará

Surgido no contexto da expansão mercantilista, o Brasil nasce da necessidade de obtenção e acumulação de riquezas, pela burguesia lusitana, em um contexto no qual a Igreja (Católica) e o Estado (Portugal) encontram-se profundamente imbricados. Nas terras avistadas por Cabral em 1500, somente em 1534, com a instalação das capitanias hereditárias, foi dado início ao processo efetivo de presença do colonizador. Entretanto, os inúmeros problemas resultantes do referido modelo, ancorado em donatários particulares e ao sabor de suas capacidades e iniciativas, levaram o rei de Portugal, D. João III, a tomar uma iniciativa mais ousada e envolver a monarquia na ocupação da nova terra. Nota-se que a manutenção da colônia subordinada a Coroa foi um pressuposto essencial da sustentação dos colonizadores. Todavia, logo tiveram que conviver com uma crescente contradição: entre os interesses de suas elites, que pretendiam benefícios diretos das relações com as colônias; os interesses de Estado, de preservar relações equilibradas entre metrópoles e colônias, capazes de perdurar indefinidamente; e os interesses que se formaram nas colônias, das elites coloniais associadas aos representantes do sistema de poder delegado pelas metrópoles.

O próprio mecanismo de subordinação, que levou os filhos das elites coloniais a estudar nos principais centros europeus, funcionou com o duplo significado de reproduzir a dominação ideológica e de transmitir as contradições da metrópole para as colônias, possibilitando e/ou ampliando a percepção das elites coloniais para os problemas econômicos e políticos que lhes geravam entraves, afetando seus interesses particulares. Tais interesses correspondiam ao estágio de implantação e desenvolvimento do modo de produção capitalista, em algumas regiões da Europa, e que precisa ser sustentado com os produtos e a mão-de-obra obtidos não só em seus territórios, mas inclusive no além-mar. Para a empreitada da colonização, Estado e Igreja desempenharam papel significativo. Diversas bulas papais, promulgadas no século XV, encorajavam a expansão dos países católicos e a escravização dos pagãos, considerados "inimigos do nome de Cristo". O discurso religioso alimentou o impulso colonizador. As ordens religiosas, com suas atividades concretas, incluindo as educativas, tanto na modalidade de catequese como na implantação de colégios e seminários, reforçavam o modelo que convinha aos interesses dos grupos estabelecidos nas estruturas de poder.

Em 1549 a Coroa Portuguesa assume maior controle econômico e político através do Governador-Geral, Tomé de Souza, que trouxe consigo 4 padres e 2 irmãos jesuítas, chefiados por Manoel da Nóbrega. Concomitantemente, desenvolveu-se uma nova fase de ocupação e exploração, na qual o Colégio Jesuítico ganhou destaque. Os religiosos jesuítas e de outras Ordens, chegavam com a missão de converter os gentios, e manter os colonos na "santa fé católica", da qual o rei apresentava-se como principal interessado na sua propagação e defesa. E também para assumirem o processo educativo que, na época, tinha fortes propósitos morais. Colonização, catequese e educação são, portanto, três aspectos de um grande movimento através do qual se deu a inserção do Brasil no mundo ocidental e cristão. E assim foram fixados os valores e padrões culturais, políticos e econômicos que 
convinham ao colonizador português, sobre a população nativa, como instrumento de imposição ideológica.

Até o período que antecedeu o reinado de D. José I e o conseqüente predomínio do Marquês de Pombal na condução da política lusa, a educação escolar, tanto em Portugal quanto no Brasil, não só era conduzida pelas Ordens religiosas como estava subordinada a seus interesses. Como ainda não havia separação Igreja e Estado, uma parcela dos impostos era destinada às atividades da Igreja e desta forma, pode-se dizer que o financiamento da educação era público, mas os fins e os objetivos não eram definidos pelo Estado. De um modo geral, e mesmo reconhecendo a possibilidade de equívocos, acreditamos que o desenvolvimento das atividades educativas no Grão-Pará, assemelhouse ao que ocorreu na América portuguesa. As Ordens religiosas foram seus primeiros protagonistas, auxiliando a Coroa portuguesa no processo de conquista cultural da população nativa. Escolarização restrita, em um contexto histórico-social onde poucos a ela podiam ter acesso. Aos demais, a absoluta maioria, restava a catequização, embora nesta também estivesse presente o sentido educativo.

A construção do "Forte do Presépio" em 1616, embrião do que é hoje a cidade de Belém, capital do estado do Pará, marcou a presença efetiva dos portugueses na porção norte do Brasil. A colônia de ocupação que se tornou o Grão-Pará ${ }^{3}$ visava atender aos interesses mercantis e naquele contexto, isto significava o fornecimento de produtos que interessavam aos centros consumidores localizados na Europa. Para os colonos envolvidos na produção e circulação de mercadorias, o objetivo era aumentar suas fortunas. Para os administradores, ampliar os rendimentos do Estado, por exemplo, através da coleta de impostos, função para a qual serviam com muita propriedade os vários fortes espalhados por toda a região, fiscalizando o contrabando de mão-de-obra indígena e de riquezas regionais tais como as "drogas do sertão" por parte de estrangeiros. A escola (na acepção de local de ensino e aprendizado dos códigos da escrita e da leitura) não figurava como instituição desejada ou mesmo necessária, embora a educação (no sentido de socialização, de aceitações de padrões que interessavam ao colonizador) fosse valorizada. Aos religiosos cabia a tarefa educativa, seja através de escolas ou de outros meios. Cuidando da conversão do nativo à religião cristã, e introjetando novos costumes através dos aldeamentos, os missionários levavam a cabo o trabalho de catequese, e também realizavam a instrução formal.

O padre Serafim Leite, autor de monumental obra ${ }^{4}$ acerca dos Jesuítas, dedica o $2^{\circ}$ capítulo do $5^{\circ}$ livro do tomo IV à narração dos feitos dos missionários daquela Ordem no Pará. Através daquela leitura, é possível verificar-se que os professores nem sempre eram padres, pois eles eram poucos e se dedicavam preferencialmente às aulas de conteúdo mais complexo, às expedições ou aos cargos de governo; ele também revela a natureza da instrução elementar ao afirmar que "a instrução inicial no Pará foi também mais instrumento de catequese do que pròpriamenteramo profissional de ensino". (LEITE, 1943, p. 271, Tomo IV).

O processo educativo, além do aspecto relacionado com a empresa colonizadora, pode também ser explicado como resultante da necessidade de novos integrantes para o trabalho das Ordens religiosas. Importa registrar a emigração ocorrida no princípio da ocupação do Grão-Pará: chegaram mamelucos nordestinos em 1616, açorianos em 1620, portugueses de Mazagão em 1770, assim como ciganos logo a seguir; soldados, marinheiros, corsários, mercadores, administradores de enclaves lusos, mas também degredados punidos com o exílio. Segundo Bessa Freire "o padre Antonio Vieira afirma que a prisão de Limoeiro, em Portugal, foi uma das principais fontes de colonizadores 
para a Amazônia" (1987, p. 22-3). Este contingente humano representava um significativo campo para as obras catequéticas.

Os religiosos da Companhia de Jesus edificaram sua primeira igreja na localidade de Vigia, no ano de 1702, conjuntamente com a abertura de colégios e aulas de latim. Devido a grande preocupação em aperfeiçoar o processo de comunicação com os nativos, o Padre Luís Figueira elaborou a Gramática e o Dicionário da "Língua Geral" (expressão que designava o Tupi antigo ou Tupinambá), editados em 1621 e que foram de muita valia no trato com os índios.

Nos primórdios da institucionalização educacional no Grão-Pará merece destaque dois marcos: o Convento dos Franciscanos de Santo Antonio e o Convento dos Carmelitas, ambos construídos no ano de 1626. Ali funcionaram aulas de teologia, filosofia e música. A partir de 1640, funcionou em Belém, no Convento dos Mercedários, uma escola na qual era ensinado gramática latina e bons costumes, além das primeiras letras.

Os jesuítas - religiosos de maior influência educacional no Grão-Pará - fundaram o primeiro curso superior regular no ano de 1695 e controlavam 35\% dos aldeamentos existentes até o ano de 1750. Construíram o Colégio Santo Alexandre, atual sede do Arcebispado em Belém, primeiro colégio da Amazônia, onde eram administradas aulas nos níveis primário, secundário e superior. Este último, conferia aos alunos o diploma de Bacharel, Licenciado e Mestre em Artes, não obstante o curso se voltasse para a formação de novos religiosos. O Colégio da Mãe de Deus, instalado na cidade de Vigia em 1732, também figura entre as importantes obras educacionais dos jesuítas e há registros de que lá existia uma biblioteca com 1010 volumes. (ILDONE, 1991, p. 14-15).

No Grão-Pará, como em outras regiões do Brasil, as primeiras experiências pedagógicas nascem dos religiosos, visando catequizar os índios; ao mesmo tempo, ampliam o poder dos missionários e reforçam o modelo colonizador. Muito mais catequização e instrução do que propriamente educação, no sentido escolar que se aplica ao termo. A própria metrópole, Portugal, não teve naquele período, um ensino plenamente estatal. A emergência da educação como um fenômeno de aculturação tinha na catequese um poderoso sustentáculo. Tal afirmativa pode ser apoiada em importantes estudos realizados sobre o período colonial. Por exemplo, José Maria de Paiva, autor de Colonização e catequese, defendeu a tese que a educação cumpriu um papel colonial, não como algo de fora, uma força aliada, mas fundamentalmente como um componente integrado ao processo como um todo (PAIVA, 1982, p. 97). Também o autor de $O$ combate dos soldados de Cristo na terra dos papagaios, aponta que a catequese constituiuse em um esforço racionalmente feito para a conquista de homens, para acentuar a semelhança e apagar as diferenças. (BAETA NEVES, 1978, p. 45).

Quando o Estado português interferiu, o fez de forma a satisfazer as exigências dos colonos que se sentiam prejudicados com a crescente interferência dos religiosos, inclusive na comunicação que estabeleciam com os habitantes nativos. Assim, através da provisão de 12 de outubro de 1727, foi proibido o uso da língua geral ${ }^{5}$ e determinado que os missionários ensinassem aos índios a língua portuguesa. $\mathrm{O}$ Estado português, reiteradas vezes, criou obstáculos ao pouco que era realizado neste setor, determinando que algumas ordens religiosas se afastassem do Grão-Pará. Os religiosos da Piedade foram obrigados a retornar para a metrópole em fevereiro de 1758 e em abril do mesmo ano os religiosos da Beira e Minho tiveram que se recolher ao Maranhão. A culminância desse processo de interferências deu-se com a expulsão dos jesuítas em 1759, efetivada pelo todo poderoso primeiro ministro Sebastião José de Carvalho e Mello, o Marquês de Pombal.

Francisco Xavier de Mendonça Furtado, irmão de Pombal e que governou o Estado do Grão-Pará de setembro de 1751 a março de 1759 , instituiu o Diretório ${ }^{6}$, documento que 
expressa as instruções que recebeu do rei D. José I, inclusive relativas a educação. É um marco não porque tenha resultado em realizações concretas, mas pelo novo direcionamento que traçou para a educação. O Diretório, datado de 31 de maio de 1751, aborda assuntos que vão desde um maior controle para com as atividades dos religiosos, até preocupações com os nativos e em povoar a região para evitar sua invasão pelos franceses e holandeses; também trata da criação de seminários e de conventos de freiras, do financiamento do Estado, seu comércio e segurança, destacando especial importância à agricultura e às fronteiras. Num projeto ambicioso de transformar o índio em vassalo do rei, tirando-o da tutela da Igreja, D. José I exigiu empenho de Mendonça Furtado no sentido de garantir liberdade e condições de trabalho aos índios, proibindo toda e qualquer tentativa de escravizá-los, seja por leigos ou religiosos ${ }^{7}$. Buscou garantir o cumprimento de sua determinação inclusive reforçando o serviço público com os próprios índios que seriam recrutados nas aldeias e receberiam um salário para tal.

Quanto à instrução dos índios, o Diretório destacava o ensino profissionalizante já realizado com êxito pelos Jesuítas em regiões sob controle espanhol. Assim, pede ao governador que recomende aos missionários no Grão-Pará “... que os índios que forem da sua administração, os ocupem, fazendo-lhes aprender os oficios a que tiverem mais propensão [...] (DAMASCENO, 1998, p. 85).

Passados quase três anos da instituição do Diretório, Mendonça Furtado, em carta que envia ao Marquês de Pombal expressa sua preocupação com a instrução dos índios e a efetiva implantação da língua portuguesa, além de denunciar a omissão e a desobediência das Ordens religiosas quanto ao cumprimento desta tarefa:

Já o informei de que eu dei a tôdas as religiões a ordem S.Maj. para que introduzissem nas aldeias a língua portuguêsa, sendo mais próprio para conseguir êste fim o estabelecimento das escolas; tôdas me responderam que logo obedeceriam; poucas foram as que o fizeram; rara é a que hoje conserva alguma aparência dêste estabelecimento. Porque tôdas imitam a Companhia, que absolutamente desobedece e se obstinou contra êstes utilíssimos estabelecimentos, e aqui nunca o quis executar sem mais razão que a de não obedecer, como é seu antigo costume, e de compreenderem que poderiam com êle, para o futuro, perder parte dos seus interesses. (Apud DAMASCENO, 1998, p. 94).

A intenção de organizar um sistema escolar estatal, como é possível interpretar nas preocupações do governador Mendonça Furtado, não encontrou ambiente favorável para ser concretizada. Além de que, entre a edição do Diretório em 1758 e a expulsão dos jesuítas em 1759, não houve tempo hábil de ser efetivado tal empreendimento, para o qual seria necessário adequar estruturas e currículos e capacitar professores substitutos aos mestres jesuítas. Todavia, é possível inferir que havia nas recomendações de D. José I, nas intenções de Mendonça Furtado e no propósito geral do Marquês de Pombal, o germe da universalização do acesso das crianças à instituição escolar, como forma de criar uma identidade entre os súditos da coroa.

Canivez (1991, p. 18), ao estudar a relação entre Estado e educação, argumenta que o Estado pode ser concebido como a encarnação de uma idéia nacional, onde se faz 
presente a herança de tradições e a referência aos grandes feitos do passado, dando à nação "o sentido de sua identidade e de seu valor". Assim, torna-se de fundamental importância o ensino da língua, de hábitos de convivência, história nacional e até mesmo a religião como elementos integradores de uma identidade nacional, mesmo que a isto não corresponda uma igualdade geral. Desta forma, talvez o mais apropriado seja dizer que Mendonça Furtado não visava organizar um sistema escolar estatal, e sim garantir a presença e o controle do Estado na atividade educativa, seja no âmbito da socialização/ profissionalização/ instrução/ aculturamento dos índios, assim como em estudos mais avançados e destinados a formação de quadros para os serviços públicos e para as profissões liberais. Interpretadas por este prisma, as medidas efetivadas pelo governador tiveram êxito pelo menos parcial, pois conseguiu a implantação definitiva da "língua do príncipe" na região e arrancou das ordens religiosas para o âmbito do Estado o controle das atividades no campo educacional, acompanhando um movimento verificado em outras partes do mundo, relativo ao crescente processo de separação entre Estados e Igreja.

Como destaca (PETITAT, 1994, p. 141). De acordo com o Diretório, os responsáveis pelos povoados estavam obrigados a tomar providências para que os meninos aprendessem a ler e a escrever a as meninas aprendessem a bordar, cozer e demais trabalhos então considerados femininos. Tal obrigação de nada adiantou, pois não havia meios para o seu cumprimento. Além da dificuldade em encontrar professores, era muito grande a aversão das crianças com o tipo de escola existente. O governador Mendonça Furtado, alegando que mesmo em Portugal tais dificuldades também aconteciam, insistia no cumprimento do Diretório, ao afirmar que: "Quanto a aversão, que essas Crianças tem em irem ás Escolas, e aprenderem nellas, o mesmo succede ás de Portugal, porque nenhuma vay Lá por seu gosto, e sem embargo disso as obrigam, e depois estimam muito chegarem a saber". (REIS, 1993, p. 73).

O autor citado destaca também um depoimento do Ouvidor Francisco Xavier Ribeiro de Sampaio, após viagem que realizou em 1775 pela capitania do Rio Negro. O Ouvidor, afirma não ter encontrado escolas em todas as povoações, pela absoluta falta de mestres. Notável é o relato da tentativa de contratação de um professore de primeiras letras, em 1760, em Belém. Era oferecido ordenado de oitenta mil réis por ano - nas localidades do interior, o ordenado chegava a doze mil reis -, utilizando-se de rendimentos das fazendas que antes eram de propriedade dos religiosos inacianos. Mesmo assim, "ninguem queria sojeitarse ao trabalho de mestre das escolas pelo pouco lucro, q. que resultava". (REIS, 1993, p. 74). Somente em junho do ano seguinte foi nomeado um professor leigo para Belém, de nome Euzebio Luiz Pereira Lendon.

Há também relato de escassez de alunos: Em carta régia de 11 de junho de 1761, o governo português autorizou o estabelecimento de um colégio secular no hospício que os religiosos da Piedade haviam deixado na localidade de Gurupá e outro onde antes funcionava um convento dos jesuítas em Belém. Mas como a frequência foi completamente nula nestes estabelecimentos, o governador Fernando da Costa Athaide Teive achou por bem propor ao Ministério do Reino que os suprimissem.

O ensino público da capitania do Grão-Pará foi regulamentado no governo de Francisco de Souza Coutinho, a 15 de abril de 1799, com aprovação pela carta régia datada de 28 de fevereiro de 1800. Por força da referida regulamentação, Belém passou a contar com duas escolas primárias e três escolas de humanidades, e outras 13 escolas foram criadas no interior, nas seguintes localidades: Bragança, Marajó, Monsaras, Vigia, Melgaço, Cintra, Barcellos, Oeiras, Cametá, Macapá, Santarém, Monte Alegre e Gurupá. Analisando o número e o tipo de escolas regulamentadas em Belém, Vianna (1987) faz o seguinte comentário "havia mais quem estudasse latim, philosophia, mathematicas, do que 
quem precisasse das luzes do A B C." Em outro trecho comenta as instruções baixadas pelo governador em 2 de outubro de 1799:

[...] revoltado contra os barbaros castigos corporaes inflingidos aos estudantes, por professores que leccionavam custodiados pela palmatoria e pelo chicote, prescreveu elle que, de então, quando algum alumno se fizesse merecedor de castigo physico, esperassse o mestre o fim da aula e, após a sahida dos outros discipulos, requisitasse um soldado, para applicar no infeliz as palmatoadas.

Imagine-se os resultados d'esta pedagogia que entregava a um soldado boçal as mãos ou costas dos pobres estudantes! (VIANNA, 1987, p. 6).

Através de carta régia datada de 19 de agosto de 1799, o governador foi autorizado pelo Príncipe D. João, nomear e demitir os professores das escolas menores, quer fossem civis ou eclesiásticas. Antes, cabia às câmaras e ao bispo tais atribuições. O governador também passou a ser responsável pelo aumento ou supressão de cadeiras, assim como a exercer a inspeção sobre as escolas. Em sintonia com tais atribuições, o Conde de Vila Flor, último da série de capitães-generais que exerceu o governo no Grão-Pará, a 20 de novembro de 1818, dirigindo-se a membros do clero e de outros setores da sociedade, durante sessão solene de abertura das aulas no Seminário Episcopal, pronunciou discurso onde relatava a precariedade do ensino público e cobrava o descuido dos pais, por deixarem seus filhos imersos na ignorância. Organizou um programa que denominou "Systhema de Instrucção Publica", o qual enviou ao Rio de Janeiro para ser apreciado por D. João VI. Visando materializar seus intentos, criou uma Aula Militar em Belém. Mas uma série de acontecimentos relacionados com o movimento constitucionalista que explodira em Portugal e também repercutia em diversos pontos da colônia, obrigou-o a deixar o Grão-Pará em 1820, impedindo-o de levar adiante seus propósitos.

Vianna, considera que naquele período conturbado, o governo não podia atender a instrução pública, tão ocupado que estava com a sua própria sustentação política. "Sem um plano pedagogico, obedecendo á centralização absurda que subordinava ao governador todos os assumptos, sem um professorado apto para o magisterio, luctou o ensino com tropeços insuperaveis; o analfabetismo campeou em proporção assustadora.". Em seguida atribui as "carnificinas horrorosas da Cabanagem" a responsabilidade por um "ambiente nocivo ao progredimento de todos os ramos da actividade publica, que somente veio a dissipar-se depois de 1836". (VIANNA, 1987, p. 8).

Primeiro a centralização administrativa e depois a Cabanagem, são analisadas como os únicos entraves para o não desenvolvimento da educação escolar, e para justificar o agravamento de uma situação que já era caótica. Enquanto Vianna procura demonstrar que no momento em que finalmente a educação se encontrava prestes a trilhar o caminho do progresso, foi prejudicada pelo "ambiente nocivo" gerado pela Cabanagem, encontramos na análise de outro historiador, uma nítida tendência em enaltecer a política lusa, ao enfatizar o interesse para com "o setor espiritual", minimizando seus possíveis fracassos.

A principio dellegando poderes aos religiosos, a partir de Pombal tomando a hombros o encargo, a politica de Portugal no valle amazonico, no sector espiritual, se não foi aguda, penetrante, de traços vigorosos, de exito deveras apreciavel, importou numa saudavel e muito expressiva demonstração de que a velha 
monarchia iberica não se mostrou indifferente á intelligencia dos homens do extremo-norte do Brasil, antes mesmo procurando animal-a, movimental-a, dar-lhe agilidade. (REIS, 1993, p. 80).

O fato é que nas últimas décadas do século XVIII, assim como nas primeiras décadas do século XIX, a educação escolar, embora aparentemente ocupando espaço nas preocupações dos governantes, esteve longe de objetivar a universalização. Pelo contrário, reforçava a discriminação e as desigualdades de classe.

\section{Considerações finais}

Com base na concepção adotada e defendida nesta exposição, entendemos que aslutas desencadeadas na perspectiva da emancipação humana, são profundamente educativas, na medida em que apontam para a superação de todasas formas de opressão, mantendo, contudo, o aprendizado intrínseco ao modo de vida em sociedade, com suas particularidades. Diferentemente de outros animais, biologicamente destinados a uma determinada tarefa, a herança genética do homem não garante a vida social, coletiva. É preciso aprender. Daí a educação ser um vínculo entre o conhecimento e ação. De tal forma que: "A história só é possível quando o homem não começa de novo e do princípio, mas se liga ao trabalho e aos resultados obtidos pelas gerações precedentes". (KOSIK, 1976, p. 18).

Reconhecendo-se e aceitando-se a afirmação de que a história deve ser entendida como "a história de lutas de classes" (MARX e ENGELS, 1982, p. 106), cabe ao pesquisador inserido nesta área e cujo objeto de estudo esteja demarcado no campo da ciência história, desvelar os embates que foram travados pelas forças sociais na fase histórica delimitada para o estudo e neste percurso identificar, entender e descrever as formas pelas quais o objeto investigado reflete tais antagonismos. Os registros e relatos disponíveis geralmente priorizam os feitos de grandes vultos ou grupos, constituindo-se em uma história política, unifacetária. É preciso, como afirma Rossi (1981, p. 11) “[...] recuperar na história da educação as contribuições que, por não atenderem aos interesses dos dominados, foram obscurecidas, relegadas a um segundo plano ou mesmo inteiramente esquecidas". Trata-se de uma tarefa inadiável, e para a qual é imprescindível a utilização criteriosa de um referencial teórico metodológico que possibilite a leitura da realidade tendo em vista as suas múltiplas determinações.

Chamar a atenção para a ausência, o negligenciamento ou mesmo a desqualificação no debate quanto às questões teórico-metodológicas presentes em um determinado trabalho não significa negar a sua contribuição. Vários trabalhos possuem o mérito de trazer à tona informações valiosas e inéditas acerca do cotidiano de nossas escolas, bem como de práticas educativas não institucionais, assim como revelam-se excepcionais na identificação e exploração de novas fontes. O que se critica neles são os limites impostos pela própria natureza da concepção na qual estão apoiados e que não permite e nem admite buscar entender as relações entre o particular e o geral, entre o discurso e a prática efetiva, entre o imaginário e a base material concreta. Por outro lado, isto corresponde também a dizer que para o pesquisador historiador da educação que opte pela concepção materialista histórica há um desafio ainda maior, qual seja: incorporar e superar as contribuições apresentadas por estudos decorrentes da aplicação de outras concepções caso tenham se limitado ao registro das memórias, quaisquer que sejam elas. 


\section{Referências Bibliográficas:}

BAETA NEVES, Luis Felipe. O combate dos soldados de Cristo na terra dos papagaios: colonialismo e repressão cultural. Rio de Janeiro: Forense Universitária, 1978.

BESSA FREIRE, José Ribamar. (Coord.). A Amazônia no período colonial (1616-1798). Manaus: Fundação Universidade do Amazonas, 1987.

BETTENDORFF, Pe. Felipe. Crônica da missão dos padres da Companhia de Jesus no estado do Maranhão. Belém: fundação cultural do Pará, 1980.

CANIVEZ, Patrice. Educar o cidadão? Campinas/SP: Papirus, 1991.

DAMASCENO, Alberto. Origens da educação estatal na América portuguesa. 1998. Tese (Doutorado). Pontifícia Universidade Católica de São Paulo.

FARIA FILHO, Luciano Mendes de. VIDAL, Diana Gonçalves. Os tempos e os espaços escolares no processo de institucionalização da escola primária no Brasil. In: Revista Brasileira de Educação. São Paulo: ANPED: Autores Associados, 2000. [Edição Especial $\mathrm{n}^{\mathrm{o}}$ 14, mai/jun/jul/ago 2000].

ILDONE, José. Noções de história da Vigia. Pará: CEJUP 1991.

LEITE, Serafim. História da companhia de Jesus no Brasil. 1943. Lisboa: Portucália. Rio de Janeiro: Instituto Nacional do Livro, 1943. [Tomo IV].

MARX, K. O capital: critica da economia política. vol. 1, Posfácio da segunda edição, São Paulo: Abril Cultural, Os Economistas, 1983.

MENDONÇA, Marcos Carneiro de. (ed.) A Amazônia na era pombalina: correspondência inédita do governador e capitão-general do Estado do Grão-Pará e Maranhão Francisco Xavier de Mendonça Furtado 1751-1759. (3 tomos). Rio de Janeiro: Instituto Histórico e Geográfico Brasileiro, 1963.

NOVAIS, Fernando. Portugal e Brasil na crise do antigo sistema colonial (1777-1808). $2^{a}$ ed. São Paulo: Hucitec, 1983.

ORSO, Paulino José. CASTANHA, André Paulo. História da educação: Pesquisa e memória histórica. In: ORSO, P. CASTANHA, A. SILVA, J. MARTIN, E. PERES, C. (Orgs.) História da educação: pesquisa e memória histórica. Cascavel: Coluna do Saber, 2008

PAIVA, José Maria de. Colonização e catequese. São Paulo: Cortez, 1982.

PETITAT, André. Produção da escola/produção da sociedade. Porto Alegre: Artes Médicas, 1994.

RAGAZZINI, Dário. Para quem e o que testemunham as fontes da história da educação? In: Educar em revista n 18/2001. Curitiba. Editora EFPR, 2001 [p. 13-28].

REIS, Arthur Cézar Ferreira. Limites e demarcações na Amazônia brasileira. 2 vol. $2^{a}$.ed. Belém: Secretaria de Estado da Cultura, 1993.

SWEET, David G. y NASH, Gary B.. Lucha por la supervivencia en la América colonial. México: Fondo de Cultura Económica, 1987. 
VIANNA, Arthur. Esboço retrospectivo da instrucção publica no Pará. In: A educação no Pará. Documentário. Belém/PA: Governo do Estado do Pará: Secretaria de Estado de Educação, 1987.

Notas

${ }^{1}$ Ementa: História da educação face ao processo de formação econômica e social do Brasil e da Amazônia. Educação brasileira e amazônica nos seus aspectos político, econômico e social com ênfase às questões relativas à história da educação na Amazônia. (Fonte: http://www.ufpa.br/ce/ementas.htm).

${ }^{2}$ IX Jornada do Histedbr. Belém/PA, 07 a 09 de junho de 2010. Tema central: O nacional e o local na história da educação.

${ }^{3}$ Denominação já utilizada antes mesmo da fundação de Belém. Embora haja controvérsias sobre sua origem, a versão mais aceita credita a expressão ao vocabulário tupi, onde "pa'ra" quer dizer rio. Os primeiros navegadores - espanhóis e portugueses - batizaram de Gran-Pará o trecho de confluência dos rios Amazonas e Tocantins, por sua grande largura, assemelhando-se ao mar. Daí veio a denominação da capitania do GrãoPará, estabelecida em 1616. (QUINTILIANO, 1963, p. 49-51).

4 "História da Companhia de Jesus no Brasil", dividida em dez volumes, co-editada em 1943 pela Livraria Portucália, de Lisboa e pelo Instituto Nacional do Livro, do Rio de Janeiro.

5 Adaptação da língua tupi feita pelos jesuítas, para facilitar a catequese. Também conhecida como "tupi jesuítico" e "ñheemgatú", passou a ser a língua mais utilizada, provocando reações drásticas dos colonos portugueses, que se viam em posição de inferioridade para o exercício de seu poder, pois muitas vezes dependiam dos jesuítas como "intérpretes".

${ }^{6}$ Instrumento jurídico que vigorou de 1757 a 1798, durante o governo de Mendonça Furtado. Extinguiu o Regimento das Missões, substituindo a administração dos religiosos por leigos nos aldeamentos. Esta questão será tratada com maiores detalhes no capítulo 4.

${ }^{7}$ Há autores que relatam a participação de religiosos na escravização dos índios. Por exemplo, Mendonça (1963, p. 27) cita que uma das "tropas de resgate", fôra chefiada por um padre jesuíta chamado Aquiles Maria Avogadri, enquanto Sweet e Nash (1987, p. 321) dão destaque para um a presença de um capelão jesuíta nas expedições de "recrutamento" de mão-de-obra, legitimando a aquisição dos escravos.

Recebido em: $\quad 20 / 08 / 2011$

Aprovado em: $\quad 22 / 08 / 2011$ 